\title{
Marine green macroalgae: a source of natural compounds with mineralogenic and antioxidant activities
}

\author{
Surget Gwladys ${ }^{1}$, Roberto Vania P. ${ }^{2}$, Le Lann Klervi ${ }^{1}$, Mira Sara ${ }^{2}$, Guerard Fabienne ${ }^{1}$,

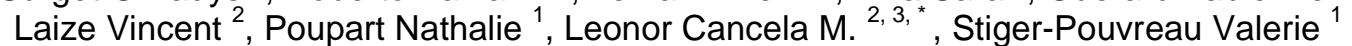

${ }^{1}$ Univ Brest, CNRS, IRD, Ifremer,LEMAR,UMR 6539,IUEM, F-29280 Plouzane, France.

${ }^{2}$ Univ Algarve, Ctr Marine Sci CCMAR, Faro, Portugal.

${ }^{3}$ Univ Algarve, Dept Biomed Sci \& Med DCBM, Faro, Portugal.

* Corresponding author : Leonor Cancela, email address :

leocancela@gmail.com; valerie.stiger@univ-brest.fr

\begin{abstract}
:
Marine macroalgae represent a valuable natural resource for bioactive phytochemicals with promising applications in therapeutics, although they remain largely under-exploited. In this work, the potential of two marine green macroalgae (Cladophora rupestris and Codium fragile) as a source of bioactive phenolic compounds was explored, and antioxidant, mineralogenic, and osteogenic activities were evaluated. For each species, a crude hydroalcoholic extract (CE) was prepared by solid/liquid extraction and fractionated by liquid/liquid purification into an ethyl acetate fraction (EAF) enriched in phenolic compounds and an aqueous fraction (AF). Antioxidant activity, assessed through radical scavenging activity and reducing power assay, was increased in EAF fraction of both species and closely related to the phenolic content in each fraction. Mineralogenic activity, assessed through extracellular matrix mineralization of a fish bone-derived cell line, was induced by EAF fractions (up to $600 \%$ for $C$. rupestris EAF). Quantitative analysis of operculum formation in zebrafish larvae stained with alizarin red S further confirmed the osteogenic potential of EAF fractions in vivo, with an increase of more than 1.5 -fold for both $C$. fragile and $C$. rupestris fractions, similar to vitamin $D$ (control). Our results demonstrated a positive correlation between phenolic fractions and biological activity, suggesting that phenolic compounds extracted from marine green macroalgae may represent promising molecules toward therapeutic applications in the field of bone biology.
\end{abstract}

Keywords : Ulvophyceae, Phenolic compounds, Antioxidant activity, Mineralogenic activity, Proliferative activity 


\section{Introduction}

A priority in biotechnological innovation in the last decade has been the exploration of natural resources towards the discovery of new and promising bioactivities, e.g. with therapeutic potential or industrial applications (reviewed in Donia \& Hamann 2003; Imhoff et al. 2011; Bonifácio et al. 2014). Surfactants for biomaterials are of particular interest to improve biocompatibility and efficacy and, in this regard, phytochemicals were found to have antioxidant capacities and also to promote osteoblast proliferation and differentiation (Habauzit \& Horcajada 2007; Woo et al. 2010; Karadeniz et al. 2014, 2015), which make them suitable for applications related to bone regeneration or increased bone density (Watson \& Schönlau 2015; Córdoba et al. 2015a,b). Marine macroalgae, beside their role in the provision of alginates, carrageenans, fibers and minerals for agrifood (Marsham et al. 2007; Mouritsen 2013; Stiger-Pouvreau et al. 2016) also represent a valuable source for bioactive phytochemicals (reviewed in Imhoff et al. 2011; Stengel \& Connan_2015). While macroalgae are largely under-exploited in Europe, they are commonly harvested in Brittany for industrial applications such as cosmetic, food, thalassotherapy and medicinal products (Bourgougnon \& Stiger-Pouvreau 2011). Brown algae are by far the most harvested species (97.2\%) followed by red $(2.7 \%)$ and green $(0.06 \%)$ algae. Among the green algae, species of the genus Ulva and Enteromorpha are mainly valorised in Brittany (Chambre syndicale des algues et végétaux marins, CSAVM, com. pers.). Phenolic compounds from marine and terrestrial plants exhibit a wide range of chemical structures (Ajila et al. 2011; Singh \& Bharate 2006) and a large spectrum of biological activities (Ksouri et al. 2012; Li et al. 2011). For example, they showed anti-diabetic (Lee \& Jeon 2013), anti-microbial (Eom et al. 2012), anti-oxidative (Le Lann et al. 2008; 2012; Andrade et al. 2013; Tanniou et al. 2013; 2014; Stiger-Pouvreau et al., 2014 ; Surget et al., 2015), photoprotective (Surget et al. 2015), anti-tumoral (Deslandes et al. 2000; Zubia et al. 2009; Montero et al. 2016), anti-inflammatory (Kang et al. 2013; Kim et al. 2009) and radioprotective effects (Liu et al. 2011). Properties of bioceramic-based medical scaffolds have been successfully improved upon supplementation with phenolic compounds from marine origin, in particular toward increased bone tissue regeneration (Yeo et al. 2012; Córdoba et al. 2015a,b). Phlorotannins, i.e. phenolic compounds from brown seaweeds, extracted from Ecklonia brown algae species have also been shown to increase alkaline phosphatase (ALP) activity, mineralization, total protein and collagen synthesis in human osteosarcoma cells (MG-63 cells) (Ali \& Hasan 2012; Ryu et al. 2009; Yeo et al. 2012; Karadeniz et al. 2015), suggesting that they may act as regulators of osteoblast differentiation 
and osteosarcoma differentiation, with an implication of phenolic compounds in the mitogenactivated protein kinase (MAPK) pathway together with enhancing collagen and mineralization in the non-cytotoxic concentration range (Ryu et al. 2009). In the context of the biotechnological valorisation of marine algae in Europe and the discovery of new bioactive molecules as potential biomaterials for regenerative medicine, this work intended to get insights into the osteogenic and antioxidant capacities of the phenolic compounds extracted from two green seaweeds, the native Cladophora rupestris and the introduced Codium fragile. In that sense, crude extracts and semi-purified fractions were evaluated for total phenolic content, anti-oxidative activity and mineralogenic and proliferative effects, in this case using a bone-derived cell line from gilthead seabream (Sparus aurata) capable of extracellular matrix mineralization (Pombinho et al. 2004). The most active fractions were then tested in vivo, using the zebrafish as a model system to assess mineralization (Laizé et al. 2014).

\section{Material and methods}

Regular reagents and materials

Solvents and chemicals (analytical grade) were from Carlo Erba Reagent and Sigma-Aldrich, respectively, unless otherwise stated. Cell culture reagents and plastic consumables were from Invitrogen and Sarstedt, respectively.

\section{Biological material}

Samples of the green seaweeds Codium fragile (Suringar) and Cladophora rupestris (Linnaeus) were collected in rockpools of Porsmeur bay (Lanildut, France, 48 28'55.67"N, $\left.4^{\circ} 46^{\prime} 14.76^{\prime \prime O}\right)$. Both species are two Ulvophyceae macroalgae. C. fragile belongs to the Bryopsidales order and the Codiaceae family and is an introduced species in Europe, with a worldwide spread. On the contrary, C. rupestris, is a native species in Brittany, widely distributed in temperate and cold temperate Atlantic Ocean, and belongs to the Cladophorales order and the Cladophoraceae family. After collection and removal of epiphytes, seaweeds were washed with deionized water, frozen, freeze-dried (Christ Beta 1-8 LD freeze dryer), grinded into powder and stored in the darkness at room temperature to limit the phenolic compounds degradation, as described in Le Lann et al. (2008). 
Extraction and liquid-liquid semi-purification process

Fifteen grams of dry powder were macerated for $2 \mathrm{~h}$ at $40^{\circ} \mathrm{C}$ in $150 \mathrm{~mL}$ of hydroethanolic solvent (1:1 distilled water/100\% ethanol mixture) under agitation (200 rotations per min) and in the dark. After centrifugation $\left(3000 \mathrm{rpm}, 15^{\circ} \mathrm{C}, 10 \mathrm{~min}\right)$, supernatant was collected and pellet was resuspended in $150 \mathrm{~mL}$ of hydroethanolic solvent and macerated for an additional $1 \mathrm{~h}$. This last step was repeated once more and the three supernatants were pooled and passed through fiberglass. Ethanol was removed at $40^{\circ} \mathrm{C}$ by vacuum evaporation and distilled water was added to obtain a $100-\mathrm{mL}$ crude extract (CE). Crude extract was separated into two semipurified extracts, an aqueous fraction (AF) and an ethyl acetate fraction (EAF) using a protocol adapted from Stiger-Pouvreau et al. (2014) to concentrate polyphenols in EAF. Briefly, lipidic compounds and chlorophyllic pigments were removed through several washes with dichloromethane then, proteins and carbohydrates were precipitated using pure acetone and $100 \%$ ethanol. Purified extract was then divided into ethyl acetate and aqueous fractions.

Total phenolic content

Total phenolic content (TPC) was determined by spectrophotometry using Folin-Ciocalteu assay (Sanoner et al. 1999) modified according to Le Lann et al. (2008). Wells of a 96-well plate were successfully filled with $20 \mu \mathrm{L}$ of extracts (dilution ranging from 1 to 0.01 g. $\mathrm{L}^{-1}$ ), $130 \mu \mathrm{L}$ of distilled water, $10 \mu \mathrm{L}$ of Folin-Ciocalteu reagent and $40 \mu \mathrm{L}$ of sodium carbonate solution $\left(200 \mathrm{~g} . \mathrm{L}^{-1}\right)$. After agitation, plate was incubated at $70^{\circ} \mathrm{C}$ for $10 \mathrm{~min}$ then placed on ice to stop the chemical reaction. Absorbance was measured at $620 \mathrm{~nm}$ using a Multiskan MS plate reader (LabSystems) and phenolic content was determined using a standard curve of gallic acid ranging from 0 to $200 \mu \mathrm{g} / \mathrm{mL}$. Results are expressed as mg of gallic acid per $\mathrm{g}$ of dried extract (DW). All measurements were performed in triplicate. 
Antioxidant assays

$D P P H$ radical scavenging activity Radical scavenging activity of extracts/fractions and positive controls was determined using the DPPH (2,2-diphenyl-1-picrylhydrasyl) assay adapted from Le Lann et al. (2008) and Zubia et al. (2009). This assay tests the capacity of samples to scavenge the synthetic radical DPPH, but is independent of sample polarity and highly reproducible (Huang et al. 2005). Briefly, $100 \mu \mathrm{L}$ of extract/fraction, positive control (6-hydroxy-2,5,7,8-tetramethylchroman-2-carboxylic acid or Trolox) or negative controls (distilled water and $100 \%$ ethanol) were added to $100 \mu \mathrm{L}$ of DPPH solution (36.9 mg.L $\mathrm{L}^{-1}$ ) in a 96-well plate. Several dilutions of extracts/fractions and positive controls (ranging from 0.005 to 1 g. $\mathrm{L}^{-1}$ ) were tested. Plate was incubated for $1 \mathrm{~h}$ in the dark and absorbance was measured at $540 \mathrm{~nm}$. Radical scavenging activity of algal extracts was calculated as previously described in Le Lann et al. (2008) and Surget et al. (2015). For each sample, a curve of extract concentration against \% of DPPH inhibition was generated to determine the concentration of extract needed to cause a $50 \%$ reduction of the initial DPPH concentration $\left(\mathrm{IC}_{50}\right.$ in $\left.\mathrm{g} . \mathrm{L}^{-1}\right)$. A high $\mathrm{IC}_{50}$ is indicative of a weak radical scavenging activity and vice-versa. All measurements were performed in triplicate.

Reducing power Reducing power (RP) of seaweeds extracts was determined following the method in Zubia et al. (2009). RP assay implies an electron transfer and tests the capacity of antioxidants to reduce $\mathrm{Fe}^{3+} /$ ferricyanide complex to the ferrous form (Huang et al. 2005). A volume of $25 \mu \mathrm{L}$ of extracts/fractions, negative controls (water and ethanol) or positive controls (Trolox) was mixed with $25 \mu \mathrm{L}$ of sodium phosphate buffer (0.2 M; pH 6.6) and 25 $\mu \mathrm{L}$ of potassium ferricyanide $\left(1 \%\right.$; w/v). Mixture was incubated for $20 \mathrm{~min}$ at $50^{\circ} \mathrm{C}$. After cooling down on ice, $25 \mu \mathrm{L}$ of $10 \%$ (w/v) trichloroacetic acid, $100 \mu \mathrm{L}$ of distilled water and $20 \mu \mathrm{L}$ of $0.1 \%$ (w/v) $\mathrm{FeCl}_{3}$ were added and mixture was incubated at room temperature for 10 min. Absorbance was measured at $620 \mathrm{~nm}$. Capacity of extracts/fractions to reduce $\mathrm{Fe}^{3+}$ was determined from $\mathrm{EC}_{50}$ in $\mathrm{g} . \mathrm{L}^{-1}$ (calculated by interpolation of a regression linear curve) and corresponds to the effective concentration of the sample to obtain an optical density equal to 0.5. All measurements were performed in triplicates. 
Cultures of bone-derived cell line VSa13

Cell culture maintenance Gilthead seabream bone-derived cell line VSa13 (Pombinho et al. 2004) was used to evaluate mineralogenic and proliferative capacities of seaweeds extracts. Cells were cultured in Dulbecco's modified Eagle medium (DMEM) supplemented with 10\% FBS (fetal bovine serum), $1 \%$ penicillin-streptomycin, $1 \%$ L-glutamine and $0.2 \%$ fungizone, and incubated at $33^{\circ} \mathrm{C}$ in a $10 \% \mathrm{CO}_{2}$-humidified atmosphere (Marques et al. 2007). Cells were sub-cultured 1:4 twice a week using trypsin-EDTA solution $(0.2 \%$ trypsine, $1.1 \mathrm{mM}$ EDTA, pH 7.4).

Cell exposure to seaweeds molecules Dry extracts/fractions from green macroalgae were dissolved in distilled water, $50 \%$ ethanol (in distilled water) or $100 \%$ ethanol according to their polarity to prepare $1000 \mathrm{X}$ stock solutions. CE, EAF and AF stock solutions were added to the culture medium to achieve concentrations of $0.05,0.5,5,50,100$ or $250 \mu \mathrm{g} \cdot \mathrm{mL}^{-1}$ for EAF and $0.5,5,50$ or $100 \mu \mathrm{g} \cdot \mathrm{mL}^{-1}$ for CE and AF. Medium supplemented with extracts/fractions was $0.2-\mathrm{mm}$ filtered before applied to the cell culture.

Cytotoxicity assay Cells were seeded in 96-well plates at a density of $10^{4}$ cells per well and further cultured until confluence. Culture medium was replaced with fresh medium containing either the vehicle (control) or algal extracts and renewed every 3-4 days. Cell viability was assessed after 9 and 18 days of exposure using the Cell Proliferation Kit XTT (AppliChem). Viability of the cells exposed to seaweeds extracts was calculated as percentage of survival in comparison with cells cultured in respective controls.

Proliferation assay Cells were seeded in 96-well plates at a density of $1.5 \times 10^{3}$ cells per well. After $24 \mathrm{~h}$, culture medium was replaced with fresh medium containing either the vehicle (control) or seaweeds extracts and renewed every 3-4 days. Cell proliferation was determined after 9 days of exposure using the Cell Proliferation Kit XTT (AppliChem). Results are presented as percentage of cell proliferation, in comparison with respective controls.

Extracellular matrix mineralization Cells were seeded in 24-well plates at a density of $5 \times 10^{4}$ cells per well. Extracellular matrix $(\mathrm{ECM})$ mineralization was induced in confluent cultures, by supplementing culture medium with $50 \mu \mathrm{g} \cdot \mathrm{mL}^{-1}$ of L-ascorbic acid, $10 \mathrm{mM}$ of $\beta$ - 
glycerophosphate and $4 \mathrm{mM}$ of calcium chloride (differentiation medium). Seaweeds extracts or vehicles were added to differentiation medium and renewed twice a week. After 17 days of culture, mineral deposition was revealed through alizarin red S (AR-S; Sigma-Aldrich) staining and quantified by spectrophotometry (Stanford et al. 1995). Results are expressed as percentage of ECM mineralization, relative to the respective controls.

\section{Quantification of in vivo mineralization}

Zebrafish larvae were exposed to increasing concentrations of EAF fractions of green macroalgae, $C$. fragile (1, 5 and $\left.10 \mu \mathrm{g} \cdot \mathrm{mL}^{-1}\right)$ and C. rupestris $\left(5,50\right.$ and $\left.100 \mu \mathrm{g} \cdot \mathrm{mL}^{-1}\right)$, and control (ethanol), from 9 to 11 days post-fertilization (dpf). Briefly, from 9 to $11 \mathrm{dpf}$, larvae were reared in a 24-well dish (2 larvae per well) placed in the dark, to avoid light degradation of the compounds, at $28.5^{\circ} \mathrm{C}$. Each well was filled with $1 \mathrm{~mL}$ of embryo medium (Westerfield 2007) supplemented with EAF, the most active fraction. Medium was renewed once a day and larvae were fed with Artemia nauplii (EG strain, INVE) twice a day. After $48 \mathrm{~h}$ of exposure, larvae were euthanatized with $168 \mu \mathrm{g} . \mathrm{mL}^{-1}$ of tricaine (MS-222; Sigma-Aldrich) and fixed in $4 \%$ paraformaldehyde in phosphate-buffered saline (PBS) for $16 \mathrm{~h}$ at $4^{\circ} \mathrm{C}$. After two washes with PBS, larvae were stained with $0.01 \%$ alizarin red S (Sigma-Aldrich) solution for $30 \mathrm{~min}$, washed twice with distilled water and maintained in $25 \%$ glycerol until analysis. AR-S fluorescence in zebrafish larvae was imaged under a MZ75 stereomicroscope (Leica) equipped with a green filter (excitation filter $546 / 10 \mathrm{~nm}$, barrier filter $590 \mathrm{~nm}$ ) and a F-view camera (Olympus). Mineralized area of the operculum was determined from the morphometric analysis of the fluorescence images using ImageJ software (National Institutes of Health) and normalized with the area of the head. Zebrafish larvae were also exposed to $1 \mathrm{fg} \cdot \mathrm{mL}^{-1}$ of D (calcitriol; Sigma-Aldrich) as a positive control.

\section{Statistical analysis}

Results are presented as the mean of at least 3 replicates with standard deviation (SD). Homogeneity of variance was tested with the Bartlett's test at the 0.05 significance level. As the sample panel was small for the in vitro tests, a Kruskal-Wallis test was performed to highlight potential significant difference. In the case of significant difference between the data, non-parametric multiple comparisons (Behrens-Fisher test) were tested using the nmpc package. Statistical analysis of ECM mineralization assay and in vivo assay was performed with GraphPad Prism 4 (GraphPad, La Jolla, CA) using one-way ANOVA followed by 
Dunnett's or Tukey's multiple comparisons tests, respectively, to determine statistical differences among groups. Differences were considered statistically significant for $\mathrm{p}<0.05$.

\section{Results}

Total phenolic contents and antioxidant activities

Total phenolic content (TPC) was determined in the crude extract (CE) and semi-purified fractions (EAF and AF) of Codium fragile and Cladophora rupestris (Table 1). While all the three fractions prepared from $C$. rupestris presented high phenolic contents (ranging from

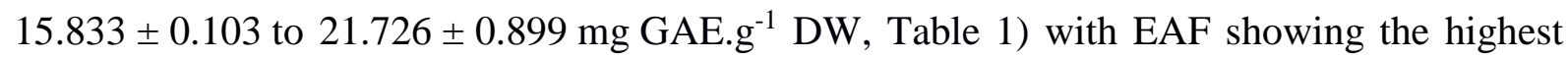
TPC, only EAF prepared from $C$. fragile exhibited a high TPC value, 10-fold higher than CE content $\left(22.381 \pm 0.206\right.$ and $2.202 \pm 0.103 \mathrm{mg} \mathrm{GAE} . \mathrm{g}^{-1} \mathrm{DW}$, respectively; Table 1). AF

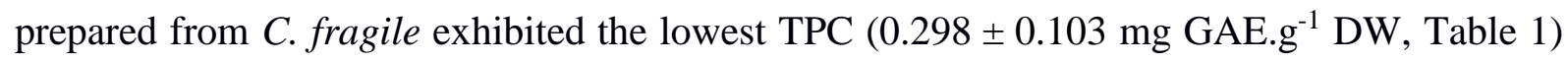
indicating an absence of aromatic compounds in this fraction. Antioxidant activities of each extract and those from the three positive controls (Trolox, BHA and ascorbic acid) were determined through the measurement of DPPH radical scavenging activity and reducing power, and expressed as $\mathrm{IC}_{50}$ and $\mathrm{EC}_{50}$, respectively. In both assays, antioxidant activity was significantly higher in the ethyl acetate fractions of both species when compared to crude extracts and aqueous fractions (Table 1). Even though, EAF antioxidant activities were lower than the positive controls tested. The lowest antioxidant activity (i.e. high $\mathrm{IC}_{50}$ and $\mathrm{EC}_{50}$ ) was always found in AF. Our data indicates that highest antioxidant activities were associated with EAF, which have the highest phenolic content, whereas lowest antioxidant activities were associated with aqueous fractions, exhibiting the lowest phenolic content.

Proliferative and mineralogenic activities of seaweeds extracts

Seaweeds extracts were further characterized for their capacity to alter cell proliferation and ECM mineralization (Figs. 1,2). Cytotoxicity of the extracts/fractions was first evaluated to determine non-toxic concentrations to be tested in subsequent assays. In that sense, cell viability was evaluated at 9 days (endpoint to assess cell proliferation) and 18 days (endpoint to assess extracellular matrix mineralization) using a wide range of extract/fraction concentrations and presented as cell survival rates. Survival rates were not concentrationdependent and always above $80 \%$ for all samples/concentrations at 9 days (Fig. 1B) and above $75 \%$ at 18 days (Fig. 2B). All concentrations were further used to evaluate proliferative and mineralogenic activities of the extracts. 
Effect of seaweeds molecules on cell proliferation For both C. fragile and C. rupestris none of the extracts/fractions evidenced a pro-proliferative effect at the concentrations tested (Fig. 1A). At the highest concentrations (50 and $100 \mu \mathrm{g} \cdot \mathrm{mL}^{-1}$ ), the AF of C. rupestris presented a statistically significant negative effect of $10.7 \%$ and $13.6 \%$ respectively, compared to the control (Fig. 1A) likely indicating a toxic effect of the highest doses tested, also supported by the fact that cell survival was also negatively affected with the same doses (Fig. 1B).

Effect of the EAF fractions on ECM mineralization Alizarin red staining revealed that mineralization of VSa13 extracellular matrix was strongly increased (80\% over control cultures) upon chronic exposure to the highest concentration $\left(50 \mu \mathrm{g} \cdot \mathrm{mL}^{-1}\right)$ of both ethyl acetate fractions (Fig. 2A). In the case of $C$. rupestris EAF, pro-mineralogenic effect increased with concentration indicating a dose-dependency. Aqueous fraction of $C$. fragile (50 $\left.\mu \mathrm{g} . \mathrm{mL}^{-1}\right)$ significantly increased mineral deposition (30\% over control cultures)' but no increase was observed at higher concentration indicating that this result might not be of biological significance. To further validate the pro-mineralogenic effect of ethyl acetate fractions, new EAFs prepared from the same algal powder were prepared and evaluated for their capacity to increase ECM mineralization using an increased range of concentrations 5, 50, 100 and $250 \mu \mathrm{g} \cdot \mathrm{mL}^{-1}$. Highest concentrations of $C$. fragile EAF (100 and $\left.250 \mu \mathrm{g} \cdot \mathrm{mL}^{-1}\right)$ were found to be toxic to the cells (data not shown) and therefore were not tested for mineralogenic activity. At 5 and $50 \mu \mathrm{g} \cdot \mathrm{mL}^{-1}$, new EAF of $C$. fragile induced mineral deposition by $50 \%$ and $370 \%$, respectively, when compared to the control, indicating a dose dependent effect (Fig. 3A). Similarly, new EAF of $C$. rupestris stimulated ECM mineralization in a dose-dependent manner, reaching a $630 \%$ increase over the control at the highest concentration $\left(250 \mu \mathrm{g} \cdot \mathrm{mL}^{-1}\right)$ (Fig. 3B). These data further confirmed the mineralogenic potential of ethyl acetate fractions prepared from both green macroalgae. For the same concentrations, the effect was higher in the second assay (recent extracts).

In vivo effect of the ethyl acetate fractions on bone-mineralized area

To further study the osteogenic action of both phenolic-enriched seaweeds extracts, zebrafish larvae were exposed to ethyl acetate fractions and, in vivo bone formation and mineralization were assessed through the histomorphometric analysis of the operculum of exposed versus control larvae. After $48 \mathrm{~h}$ of exposure, larvae were immersed in alizarin red S, a calcium- 
specific dye, to stain mineralized bone structures (Gavaia et al. 2000; Bensimon-Brito et al. 2016), which at this age (11 dpf) are mainly localized in the head. The operculum is among the first structures to develop and also straightforward to identify (Laizé et al. 2014) and its area was measured to assess EAF osteogenic activity. As expected from previous studies (Fleming et al. 2005), vitamin D (used here as a positive control) increased the mineralized area of zebrafish operculum approximately 1.5 fold over vehicle, therefore validating our experiment (Fig. 4). Ethyl acetate fractions of both $C$. fragile and $C$. rupestris also increased the mineralized area of zebrafish operculum (Fig. 4). At 1, 5 and $10 \mu \mathrm{g} . \mathrm{mL}^{-1}, C$. fragile EAF significantly increased the mineralized area up to approximately 1.8 -fold change over the vehicle (Fig. 4A). Higher concentrations were tested but were lethal to the larvae (data not shown). At 50 and $100 \mu \mathrm{g} . \mathrm{mL}^{-1}, C$. rupestris EAF significantly increased the mineralized area of zebrafish operculum, up to approximately 1.6-fold change over the vehicle (Fig. 4B). Our data shows that both ethyl acetate fractions enriched in phenolic compounds increased the mineralized area of zebrafish operculum, at similar or higher levels than the positive control vitamin D.

\section{Discussion}

Marine macroalgae represent an under-expoited source of phenolic compounds with high potential for therapeutic or industrial applications. In this work, we explored the bioactive potential of extracts prepared from two marine Ulvophyceae algae, Codium fragile and Cladophora rupestris, focusing on antioxidant and osteogenic activities. The fractionation process proved to be efficient, since the phenolic content was higher in EAF from both species, although this process seems to depend on the species studied, since the aqueous fraction from $C$. rupestris, but not from $C$. fragile, presented residual levels of phenolic compounds. The difference in the polarity of phenolic compounds produced by each species could explain the differences occurred on each fraction. To further characterize the extracts/fractions prepared from green macroalgae, their antioxidant capacity was evaluated through two simple, fast, reliable and classical biochemical methods - the DPPH and Reducing Power tests - both measuring electron transfers (Huang et al. 2005). As antioxidant molecules can act through several and complex mechanisms (Frankel \& Meyer 2000), the combination of two antioxidant tests allowed us to better highlight the in vivo complexity of interactions among antioxidants in foods and biological systems (Frankel \& Meyer 2000). Our results revealed that independently of the assay or the species considered, EAF fractions exhibited the highest in vitro antioxidant activities which was also the fraction with highest 
content in phenolic compounds (Table 1), in agreement with previous studies evidencing the anti-oxidative properties of phenolic compounds (Fujii et al. 2013; Tanniou et al. 2013; Stiger-Pouvreau et al. 2014; Surget et al. 2015). Since reducing power assay depends on the redox potential of the compounds present in a sample, we propose that phenolic compounds present in the marine macrophytes EAF are probably highly efficient antioxidants against free radicals (peroxyl or hydroxyl radicals) because of their low redox potential (Zhu et al. 2002). Various natural compounds with antioxidant activity have been reported to influence biological and pathological processes, including bone mineralization and their therapeutic use in bone diseases, such as osteoporosis, or as nanocoatings to functionalize biomaterials by promoting cell adhesion and differentiation (Karadeniz et al. 2015; Watson \& Schönlau 2015; Córdoba et al. 2015a,b). In agreement, our in vitro and in vivo data clearly demonstrated the mineralogenic and osteogenic properties of $C$. fragile and $C$. rupestris $\mathrm{EAF}$, the fractions with higher phenolic content and higher antioxidant activity. In vitro assays on VSa13 cells exposed to all the extracts/fractions here purified, evidenced that only EAF of both species increased ECM mineralization, probably by promoting cell differentiation since no proliferative effect was observed. A pro-mineralogenic effect of phenolic compounds from higher plants was previously shown in mouse osteoblastic MC3T3-E1 cells by promoting calcium deposition alone (Hagiwara et al. 2011) or in combination with increased cell viability, alkaline phosphatase activity and collagen synthesis (Ding et al. 2010). Similar promineralogenic effects were obtained with phlorotannins from brown algae on the human fetal lung fibroblast MRC-5 cells (Ryu et al. 2009) or human osteosarcoma MG-63 cells (Ryu et al. 2009; Yeo et al. 2012). Furthermore, the high potential of $C$. fragile and $C$. rupestris phenolic compounds as pro-mineralogenic phytochemicals for biomedical applications was confirmed through our in vivo assay based on developing zebrafish larvae. The mineralized area of the operculum (a dermal bone derived from neural crest cells; Eames et al. 2012) was increased in fish exposed to EAF fractions, at similar levels promoted by vitamin D (positive control), indicating a pro-osteogenic activity of the compounds present in both C.fragile and C. rupestris phenolic-enriched fractions, validating our in vitro data, and reinforcing the promineralogenic activity of these fractions.

As a conclusion, the ethyl acetate fraction, which is rich in phenolic compounds, evidenced high antioxidant activity and high mineralogenic effect, promoting ECM mineralization of osteoblast-like cells in vitro and increasing the mineralized area of the zebrafish operculum in vivo. Thus, this study emphasized the biological potential of marine macroalgae and especially the use of invasive species, such as Codium fragile, for future biomedical 
applications related to the improvement of bone status. To our knowledge, this is the first report of pro-mineralogenic activity in extracts/fraction prepared from two green macroalgae C. fragile and $C$. rupestris. Moreover, we demonstrated also the suitability of using zebrafish as a model for the screening of osteogenic and mineralogenic natural products.

Even though the identification of the active phenolic compound(s) responsible for EAF fractions activities was not the objective of this study, compounds such as bromophenols, coumarin or derivative from vanillic acids are known to be produced by green algae (Stengel et al. 2011), and could be the pro-mineralogenic compounds in these extracts. In that regard, future studies should be conducted to isolate, identify and test separately the bioactive compounds present in EAF of both Ulvophyceae C. fragile and C. rupestris in order to better understand their mechanisms of action.

Acknowledgments This work was financed by the European Regional Development Fund (ERDF) - Atlantic Area Programme through MARMED project (grant no. 2011-1/164), the European Era-Net, Seas-era program through the project INVASIVES (grant no. ANR-12SEAS-0002-01) and by the Portuguese Foundation for Science and Technology (FCT) through project UID/Multi/04326/2013. The authors thank Paulo Gavaia for his help with the in vivo zebrafish system.

\section{References}

Ajila CM, Brar SK, Verma M, Tyagi RD, Godbout S, Valéro JR (2011) Extraction and analysis of polyphenols: recent trends. Crit Rev Biotechnol 31: 227-249

Ali TF, Hasan T (2012) Phlorotannin-incorporated mesenchymal stem cells and their promising role in osteogenesis imperfecta. J Med Hypotheses Ideas 6: 85-89

Andrade PB, Barbosa M, Matos RP, Lopes G, Vinholes J, Mouga T, Valentão P (2013) Valuable compounds in macroalgae extracts. Food Chem 138: 1819-1828

Bensimon-Brito A, Cardeira J, Dionísio G, Huysseune A, Cancela ML, Witten PE (2016) Revisiting in vivo staining with alizarin red S - a valuable approach to analyse zebrafish skeletal mineralization during development and regeneration. BMC Developmental Biology 16: 2-9

Bonifácio BV, da Silva PB, Aparecido dos Santos Ramos M, Silveira Negri KM, Bauab TM, Chorilli M (2014) Nanotechnology-based drug delivery systems and herbal medicines: a review. International Journal of Nanomedicine 9: 1-15 
Bourgougnon N, V Stiger-Pouvreau (2011) Chapter 4: Chemodiversity and Bioactivity within Red and Brown Macroalgae Along the French coasts, Metropole and Overseas Departements and Territories. In Handbook of Marine Macroalgae: Biotechnology and Applied Phycology (ed S.-K. Kim), pp. 58-105

Córdoba A, Satué M, Gómez-Florit M, Hierro-Oliva M, Petzold C, Lyngstadaas SP, González-Martín ML, Monjo M, Ramis JM (2015a) Flavonoid-Modified Surfaces: multifunctional bioactive biomaterials with osteopromotive, anti-inflammatory, and antifibrotic potential. Advanced Healthcare Materials 4(4): 540-549

Córdoba A, Monjo M, Hierro-Oliva M, González-Martín ML, Ramis JM (2015b) Bioinspired quercitrin nanocoatings: a fluorescence-based method for their surface quantification, and their effect on stem cell adhesion and differentiation to the osteoblastic lineage. ACS Appl Mater Interfaces 7(30): 16857-16864

Deslandes E, Pondaven P, Auperin T, Roussakis C, Guezennec J, Stiger V, C Payri (2000) Preliminary study of the in vitro antiproliferative effect of a hydroethanolic extract from the subtropical seaweed Turbinaria ornata (Turner) J. Agardh on a human non-small-cell bronchopulmonary carcimona line (NSCLC-N6). Journal of Applied Phycology 12: 257262

Ding Y, Liang C, Yang SY, Ra JC, Choi EM, Kim J-A, Kim YH (2010) Phenolic Compounds from Artemisia iwayomogi and Their Effects on Osteoblastic MC3T3-E1 Cells. Biol Pharm Bull 33: 1448-1453

Donia M, Hamann MT (2003) Marine natural products and their potential applications as antiinfective agents. THE LANCET Infectious Diseases 3: 338-348

Eames BF, Amores A, Yan Y-L, Postlethwait JH (2012) Evolution of the osteoblast: skeletogenesis in gar and zebrafish. BMC Evolutionary Biology 12: 27-40

Eom S-H, Kim Y-M, Kim S-K (2012) Antimicrobial effect of phlorotannins from marine brown algae. Food Chem Toxicol 50: 3251-3255

Fleming A, Sato M, Goldsmith P (2005) High-Throughput in vivo screening for bone anabolic compounds with Zebrafish. Journal of Biomolecular Screening 10(8): 823-831

Frankel EN, Meyer AS (2000) The problems of using one-dimensional methods to evaluate multifunctional food and biological antioxidants. J Sci Food Agric 80: 1925-1941

Fujii Y, Tanaka R, Miyake H, Tamaru Y, Ueda M, Shibata T (2013) Evaluation for antioxidative properties of phlorotannins isolated from the Brown alga Eisenia bicyclis, by the H-ORAC method. Food Nutr Sci 04: 78-82 
Gavaia PJ, Sarasquete C, Cancela ML (2000) Detection of Mineralized Structures in Early Stages of Development of Marine Teleostei Using a Modified Alcian Blue-Alizarin Red Double Staining Technique for Bone and Cartilage. Biotechnic \& Histochemistry 75(2): $79-84$

Habauzit V, Horcajada M-N (2007) Phenolic phytochemicals and bone. Phytochem Rev 7: $313-344$

Hagiwara K, Goto T, Araki M, Miyazaki H, Hagiwara H (2011) Olive polyphenol hydroxytyrosol prevents bone loss. Eur J Pharmacol 662: 78-84

Huang D, Ou B, Prior RL (2005) The chemistry behind antioxidant capacity assays. J Agric Food Chem 53: 1841-1856

Imhoff JF, Labes A, Wiese J (2011) Bio-mining the microbial treasures of the ocean: New natural products. Biotechnology Advances 29: 468-482.

Kang Y-M, Eom S-H, Kim Y-M (2013) Protective effect of phlorotannins from Eisenia bicyclis against lipopolysaccharide-stimulated inflammation in HepG2 cells. Environ Toxicol Pharmacol 35: 395-401

Karadeniz F, Ahn B-N, Kim J-A, Seo Y, Jang MS, Nam K-H, Kim M, Lee S-H, Kong C-S (2015) Phlorotannins suppress adipogenesis in pre-adipocytes while enhancing osteoblastogenesis in pre-osteoblasts. Archives of Pharmacal Research 38(12): 21722182

Karadeniz F, Kim J-A, Ahn B-N, Kwon MS, Kong C-S (2014) Effect of Salicornia herbacea on osteoblastogenesis and adipogenesis in vitro. Mar Drugs 12(10): 5132-5147

Kim A-R, Shin T-S, Lee M-S, Park J-Y, Park K-E, Yoon N-Y, Kim J-S, Choi J-S, Jang B-C, Byun D-S, Park N-K, Kim H-R (2009) Isolation and identification of phlorotannins from Ecklonia stolonifera with antioxidant and anti-inflammatory properties. J Agric Food Chem 57: 3483-3489

Ksouri R, Ksouri WM, Jallali I, Debez A, Magné C, Hiroko I, Abdelly C (2012) Medicinal halophytes: potent source of health promoting biomolecules with medical, nutraceutical and food applications. Crit Rev Biotechnol 32: 289-326

Laizé V, Gavaia PJ, Cancela ML (2014) Fish: a suitable system to model human bone disorders and discover drugs with osteogenic or osteotoxic activities. Drug Discovery Today: Disease Models 13: 29-37

Le Lann K, Ferret C, VanMee E, Spagnol C, Lhuillery M, Stiger-Pouvreau V (2012) Total phenolic, size-fractionated phenolics and fucoxanthin content of tropical Sargassaceae (Fucales, Phaeophyceae) from the South Pacific Ocean: Spatial and specific variability. Phycol Res 60(1): 37-50 
Le Lann K, Jégou C, Stiger-Pouvreau V (2008) Effect of different conditioning treatments on total phenolic content and antioxidant activities in two Sargassacean species: comparison of the frondose Sargassum muticum (Yendo) Fensholt and the cylindrical Bifurcaria bifurcata R. Ross. Phycol Res 56: 238-245

Lee S-H, Jeon Y-J (2013) Anti-diabetic effects of brown algae derived phlorotannins, marine polyphenols through diverse mechanisms. Fitoterapia 86: 129-136

Li Y-X, Wijesekara I, Li Y, Kim S-K (2011) Phlorotannins as bioactive agents from brown algae. Process Biochem 46: 2219-2224

Liu M, Hansen PE, Lin X (2011) Bromophenols in marine algae and their bioactivities. Mar Drugs 9: 1273-1292

Marques CL, Rafael MS, Cancela ML, Laizé V (2007) Establishment of primary cell cultures from fish calcified tissues. Cytotechnology 55: 9-13

Marsham S, Scott GW, Tombin ML (2007) Comparison of nutritive chemistry of a range of temperate seaweeds. Food Chem 100: 1331-1336

Montero L, Sánchez-Camargo AP, García-Canas V, Tanniou A, Stiger-Pouvreau V, Russo MT, Rastrelli L, Cifuentes A, Herrero M, Ibánez E (2016) Anti-proliferative activity and chemical characterization by comprehensive two-dimensional liquid chromatography coupled to mass spectrometry of phlorotannins from the brown macroalga Sargassum muticum collected on North-Atlantic coasts. J Chromatography A 1428: 115-125

Mouritsen OG (2013) Seaweeds: Edible, Available, and Sustainable. University of Chicago Press

Pombinho AR, Laizé V, Molha DM, Marques SMP, Cancela ML (2004) Development of two bone-derived cell lines from the marine teleost Sparus aurata; evidence for extracellular matrix mineralization and cell-type-specific expression of matrix Gla protein and osteocalcin. Cell Tissue Res 315: 393-406

Ryu B, Li Y, Qian Z-J, Kim M-M, Kim S-K (2009) Differentiation of human osteosarcoma cells by isolated phlorotannins is subtly linked to COX-2, iNOS, MMPs, and MAPK signaling: Implication for chronic articular disease. Chem Biol Interact 179: 192-201

Sanoner P, Guyot S, Marnet N, Molle D, Drilleau J-F (1999) Polyphenol profiles of French cider apple varieties (Malus domestica sp.). J Agric Food Chem 47: 4847-4853

Singh IP, Bharate SB (2006) Phloroglucinol compounds of natural origin. Nat Prod Rep 23: $558-591$ 
Stanford CM, Jacobson PA, Eanes ED, Lembke LA, Midura RJ (1995) Rapidly Forming Apatitic Mineral in an Osteoblastic Cell Line (UMR 106Graphic01 BSP). The Journal of Biological Chemistry 270: 9420-9428

Stengel DB, Connan S (2015) Marine Algae: a Source of Biomass for Biotechnological Applications. Natural Products From Marine Algae. Volume 1308 of the series Methods in Molecular Biology: 1-37

Stengel DB, Connan S, Popper ZA (2011) Algal chemodiversity and bioactivity: Sources of natural variability and implications for commercial application. Biotechnology Advances 29(5): 483-501

Stiger-Pouvreau V, Bourgougnon N, Deslandes E (2016) Chapter 8. Carbohydrates from seaweeds. In: Seaweed in Health and Disease Prevention, Fleurence J \& Levine I (Eds)

Stiger-Pouvreau V, Jégou C, Cérantola S, Guérard F, Le Lann K (2014) Phlorotannins from Sargassaceae species: interesting molecules for ecophysiological and valorisation purposes. Advances in Botanical Research 71: 379-412

Surget G, Stiger-Pouvreau V, Le Lann K, Couteau C, Coiffard L, Guérard F, Poupart N (2015) Sunscreen and antioxidant photoprotective capacities of polyphenolic compounds originated from a salt-marsh plant extract from Brittany (France). Journal of Photochemistry and Photobiology B: Biology 143: 52-60

Tanniou A, Vandanjon L, Incera M, Serrano Léon E, Husa V, Le Grand J, Nicolas J-L, Poupart N, Kervarec N, Engelen A, Walsh R, Guérard F, Bourgougnon N, StigerPouvreau V (2014) Assessment of the spatial variability of phenolic contents and associated bioactivities in the invasive alga Sargassum muticum sampled along its European range from Norway to Portugal. J Appl Phycol 26: 1215-1230

Tanniou A, Serrano Léon E, Vandanjon L, Ibanez E, Mendiola JA, Cérantola S, Kervarec N, La Barre S, Marchal L, Stiger-Pouvreau V (2013) Green improved processes to extract bioactive phenolic compounds from brown macroalgae using Sargassum muticum as model. Talanta 104: 44-52

Watson RR, Schönlau F (2015) Nutraceutical and antioxidant effects of a delphinidin-rich maqui berry extract Delphinol@: a review. Minerva Cardioangiologica 63(2 Suppl): 1-12 Westerfield M (2007) The zebrafish book, 5th Edition; A guide for the laboratory use of zebrafish (Danio rerio), Eugene, University of Oregon Press. Paperback

Woo J-T, Yonezawa T, Nagai K (2010) Phytochemicals that stimulate osteoblastic differentiation and bone formation. J Oral Biosci 52: 15-21 
Yeo M, Jung W-K, Kim G (2012) Fabrication, characterisation and biological activity of phlorotannin-conjugated PCL/beta-TCP composite scaffolds for bone tissue regeneration. J Mater Chem 22: 3568-3577

Zhu QY, Hackman RM, Ensunsa JL, Holt RR, Keen CL (2002) Antioxidative activities of Oolong Tea. J Agric Food Chem 50: 6929-6934

Zubia M, Fabre MS, Kerjean V, Le Lann K, Stiger-Pouvreau V, Fauchon M, Deslandes E (2009) Antioxidant and antitumoural activities of some Phaeophyta from Brittany coasts. Food Chem 116: 693-701

\section{Figure legends}

Table 1 Phenolic content and antioxidant activities of Cladophora rupestris and Codium fragile extracts. Phenolic content and antioxidant activities (DPPH scavenging activity and reducing power) of extracts, semi-purified fractions and commercial standards (ascorbic acid, BHA and Trolox) were assayed as described in material and methods. Results were expressed as mean values \pm standard deviation, $n=3$. Different letters indicate significant difference between means according to Berhens Fisher test $(p<0.05)$. The bold characters represent the most active fraction. ( $m g$, milligram; $g$, gram; $L$, liter; GAE, Gallic Acid Equivalent; $D W$, Dried Weight extract).

Fig. 1 Effect of crude extract and semi-purified fractions of Codium fragile and Cladophora rupestris on VSa13 cell proliferation (A) and survival (B) at 9 days. Control values were determined in vehicle-treated cells and set to $100 \%$ (dotted line). Proliferation and survival data are presented as mean values \pm standard deviation, $n>5$. Asterisks indicate values significantly different from the control value according to Berhens Fisher test (** for $p<0.01$; *** for $p<0.001)$. CE, Crude Extract; EAF, Ethyl Acetate Fraction; AF, Aqueous Fraction.

Fig. 2 Effect of crude extract and semi-purified fractions of Codium fragile and Cladophora rupestris on VSa13 extracellular matrix (ECM) mineralization (A) and survival (B) at 18 days. Control values were determined from vehicle-treated cells and set to $100 \%$ (dotted line). Mineralization and survival data are presented as mean values \pm standard deviation, $n=4(\mathbf{A})$ and $n=5($ B). Asterisks indicate values significantly different from the control value according to Berhens Fisher test $(* *$ for $p<0.01$; *** for $p<0.001)$. CE, Crude Extract; EAF, Ethyl Acetate Fraction; AF, Aqueous Fraction.

Fig. 3 Effect of ethyl acetate fraction (EAF) of Codium fragile (A) and Cladophora rupestris (B) on VSa13 extracellular matrix (ECM) mineralization. Pictures of cell cultures treated with either the vehicle $(\mathrm{V})$ or different EAF concentrations and stained with alizarin red $\mathrm{S}$ are 
shown above each graph. Level of ECM mineralization in vehicle-treated cell cultures was set to $100 \%$ (dotted line). Mineralization data are presented as mean values \pm standard deviation, $\mathrm{n}=4$. Asterisks indicate values significantly different from the vehicle value (one-way ANOVA followed by Dunnett's post-hoc test, * for $p<0.05$; ** for $p<0.01$ ). N.D. - not determined.

Fig. 4 Effect of ethyl acetate fraction (EAF) of Codium fragile (A) and Cladophora rupestris (B) on the mineralization of zebrafish operculum area. Larvae at 9 days post-fertilization were exposed for $48 \mathrm{~h}$ to increasing EAF concentrations, to vehicle (V) or to $1 \mathrm{fg} \cdot \mathrm{mL}^{-1}$ of vitamin $\mathrm{D}$ (positive control). Mineralization data are presented as mean values \pm standard deviation, $n \geq 3$. Asterisks indicate values significantly different from the vehicle value (oneway ANOVA followed by Tukey's post-hoc test, * for $p<0.05$; ** for $p<0.01$; *** for $p<0.001)$. 

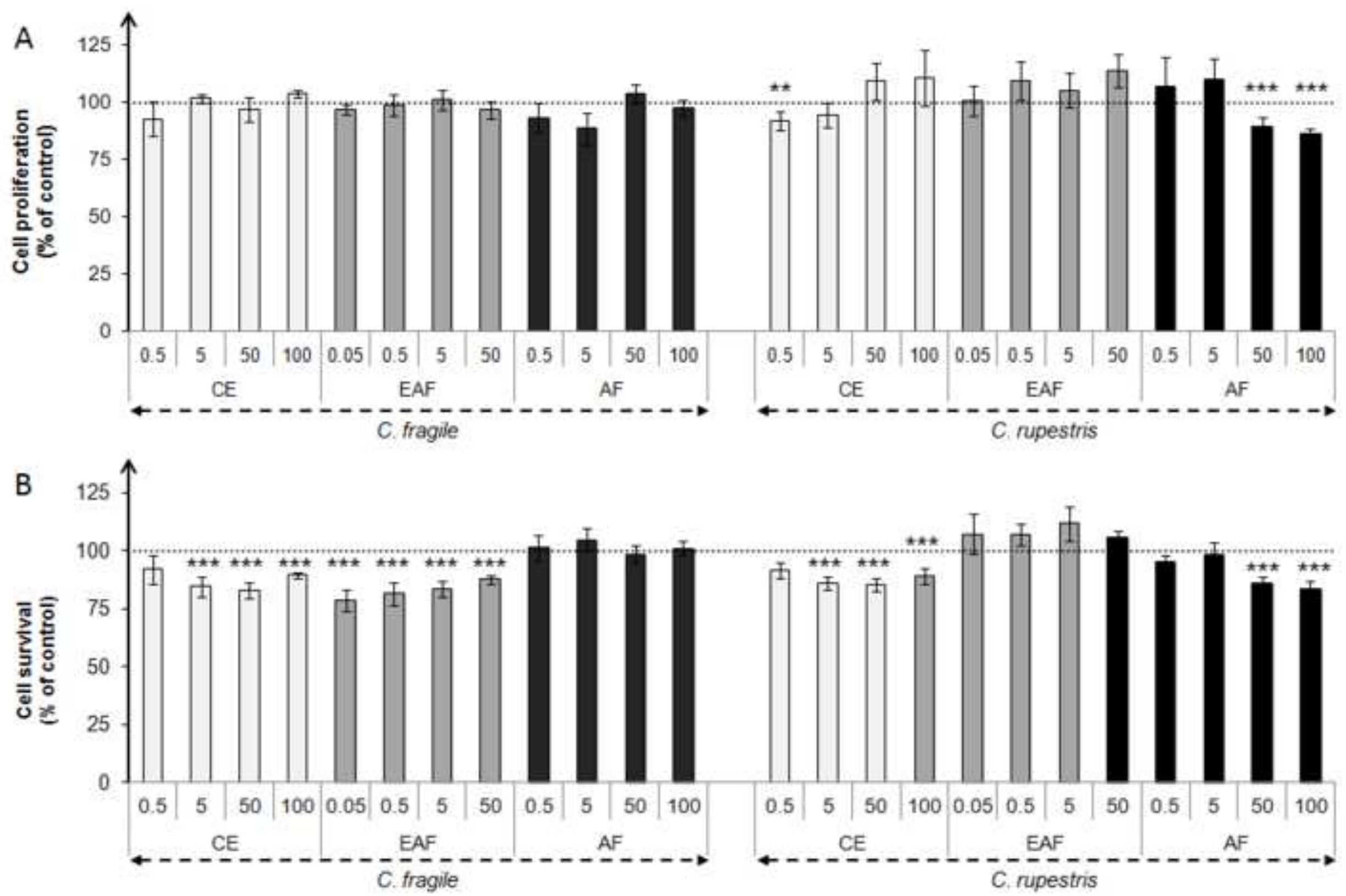

Concentrations of corresponding extracts or semi-purified fractions in cell culture medium ( $\mu \mathrm{g} \cdot \mathrm{mL}^{-1}$ ) 

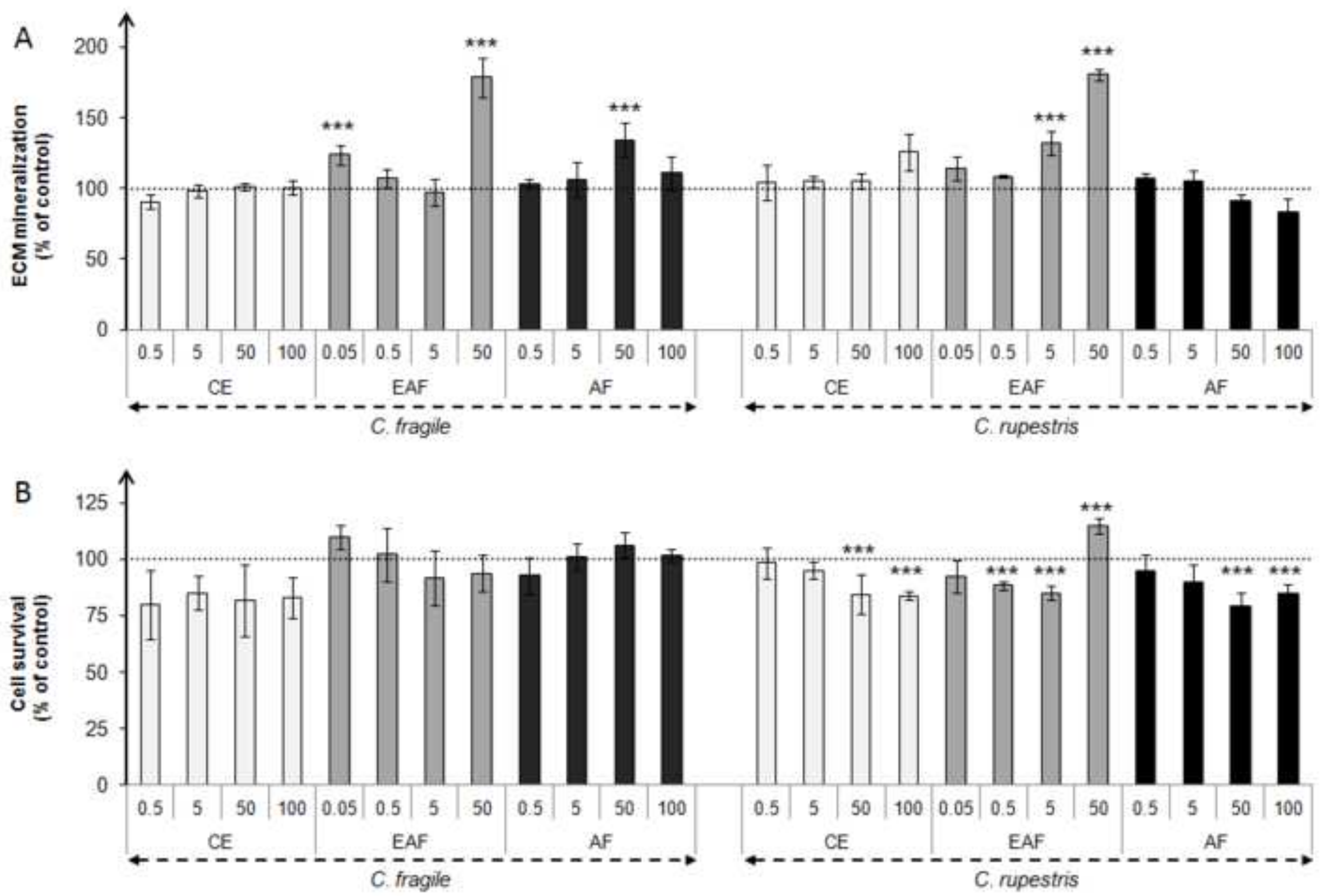

Concentrations of corresponding extracts or semi-purified fractions in cell culture medium ( $\left.\mu \mathrm{g} \cdot \mathrm{mL}^{-1}\right)$ 

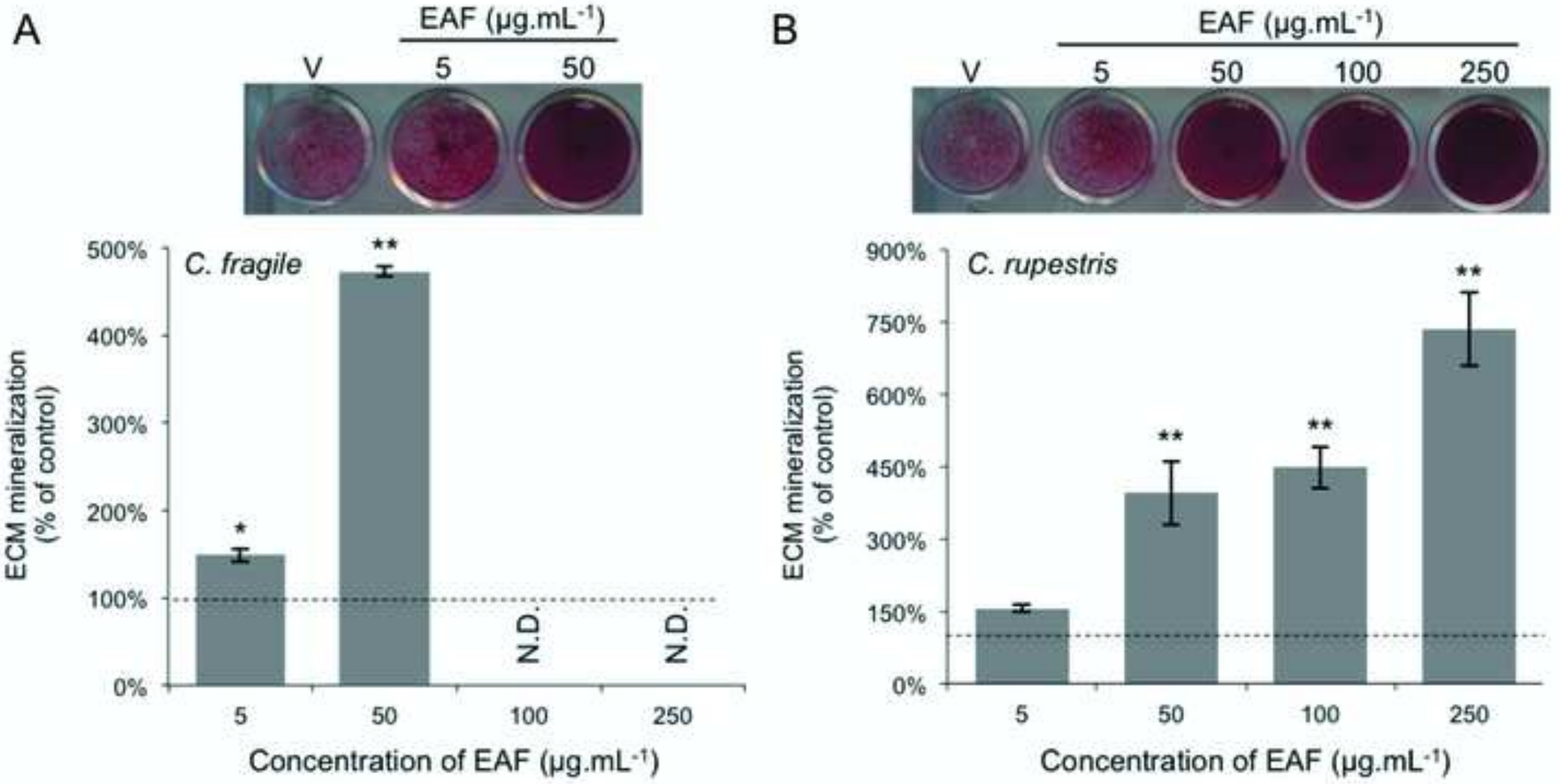


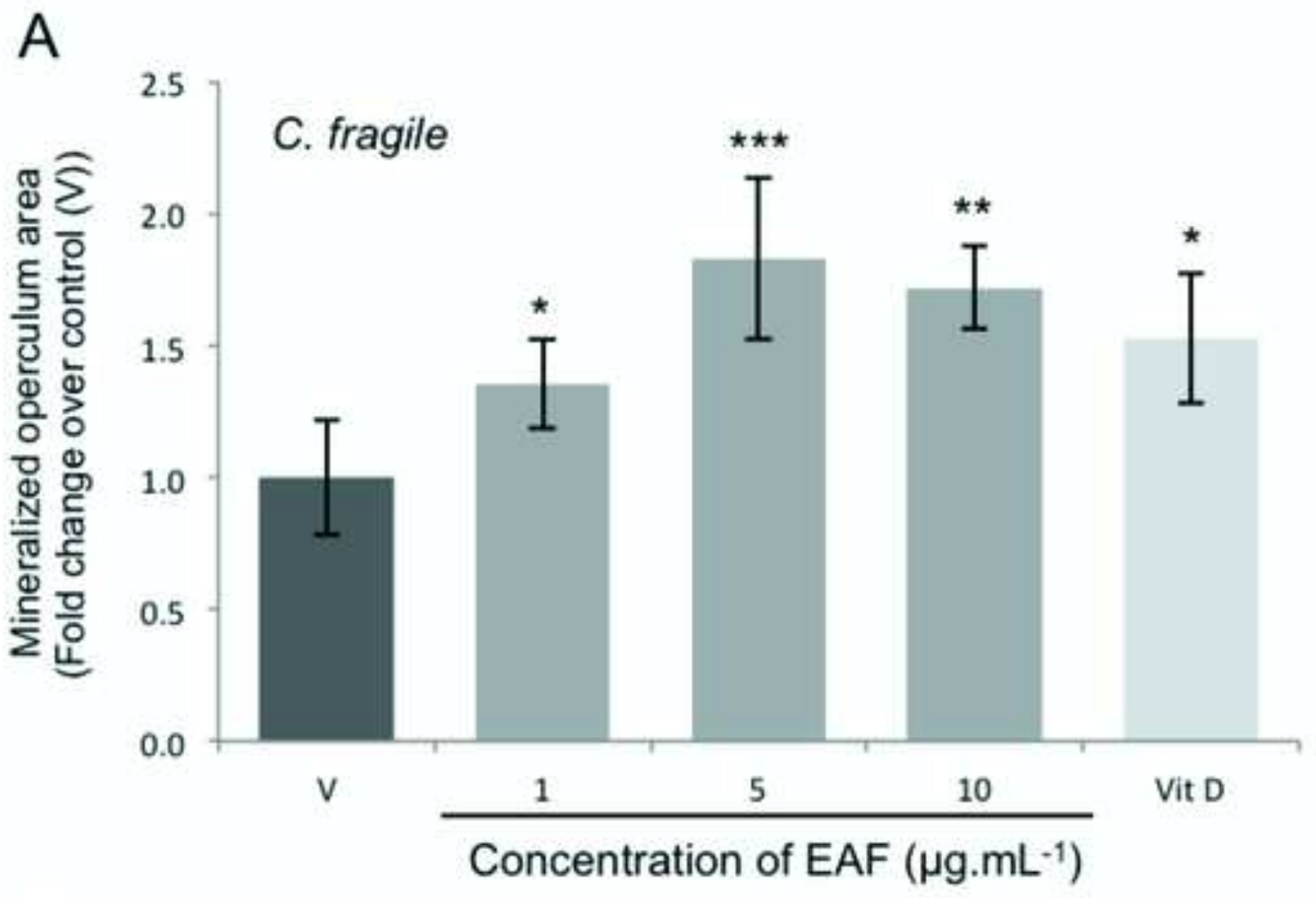

B

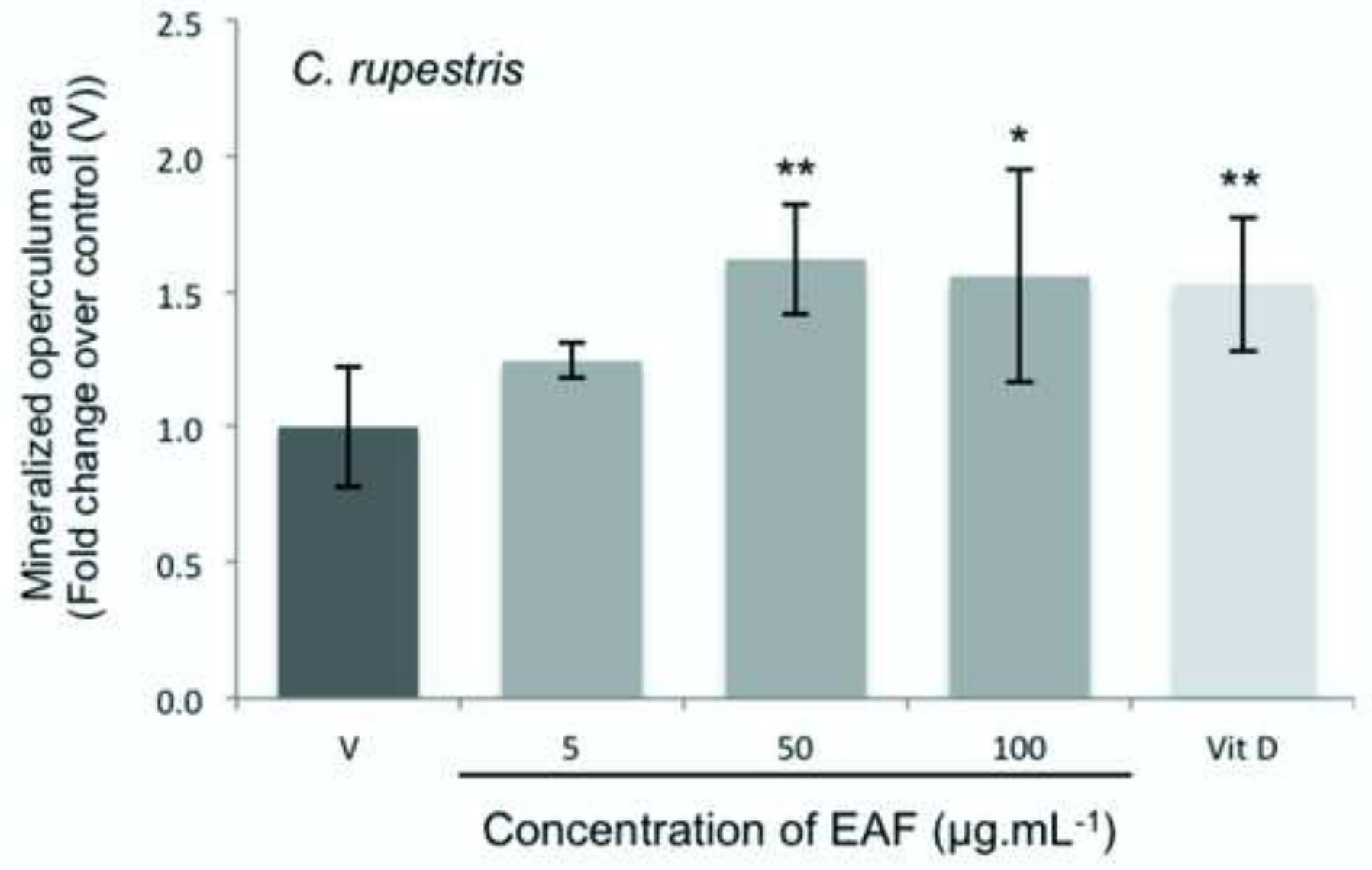


Table 1. Phenolic content and antioxidant activities of Cladophora rupestris and Codium fragile extracts. Phenolic content, DPPH scavenging activity and reducing power were determined for crude extracts and semi-purified fractions and commercial standards (ascorbic acid, BHA and Trolox). Values are expressed as mean \pm SD $(n=3)$. Different letters indicate significant difference between means according to Berhens Fisher test $(p<0.05)$. Values in bold indicate the most active fraction. GAE, Gallic Acid Equivalent; DW, Dried Weight.

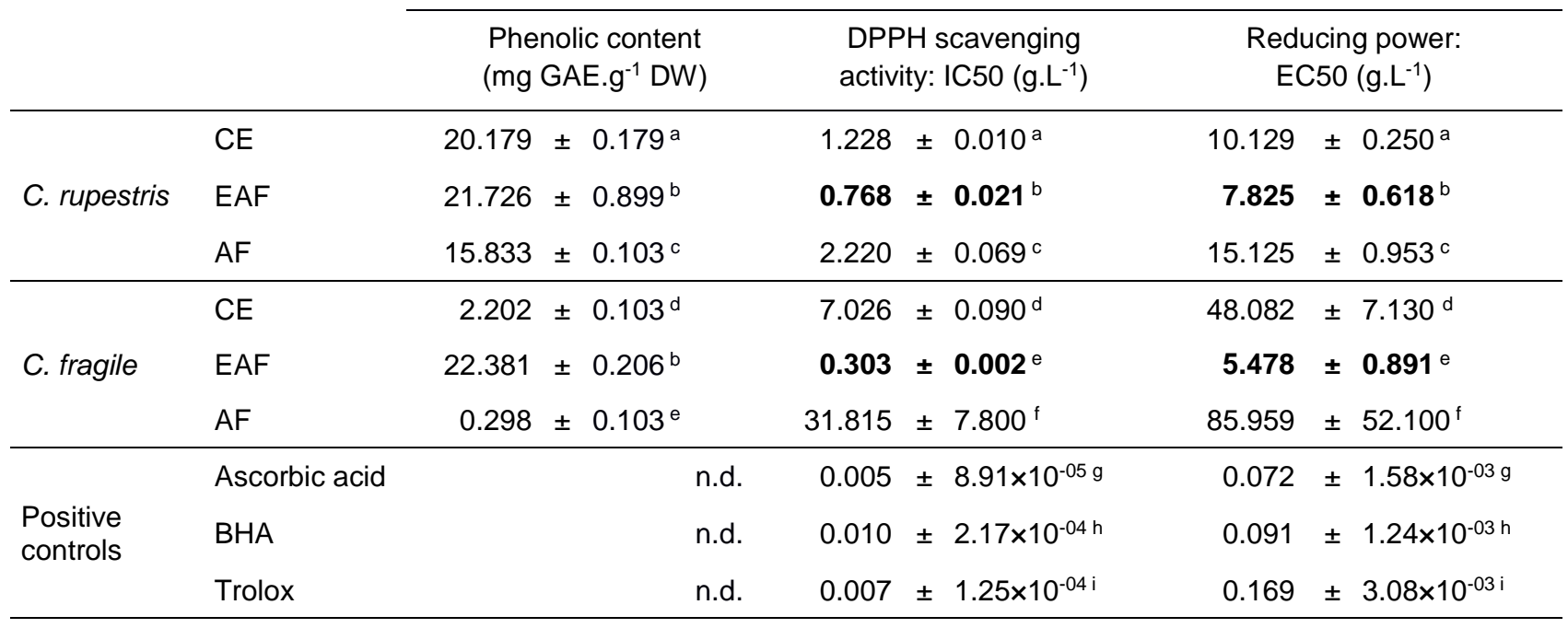

